\title{
Protective Effect of Naringenin on Cadmium-induced Toxicity in Rat Liver
}

Ke Wang, Lulu Ding, Congying Kou, Ruxue Huang, Pengli Zhao, Zijun Yang, Jicang Wang

10.18805/IJAR.BF-1425

\begin{abstract}
Background: Cadmium (Cd) is a widespread environmental toxic heavy metal. Naringin (Nar) is reported to have a protective effect on Cd-induced liver injury. This study aimed to explore the hepatic injury induced by $\mathrm{Cd}$ and the protective effects of Nar on Cdinduced oxidative stress and apoptosis in rat liver.

Methods: In accordance with groups, male SD rats were injected intraperitoneally with Cd and orally with Nar every day. The treatment period was 3 weeks. Body weight, the morphological changes in liver, the activity of antioxidant indices and expression of the apoptotic genes caspase- 3 and -9 were assessed.

Result: Results showed that the body weight of Cd-exposed rats decreased, the superoxide dismutase and catalase activities in liver decreased, the glutathione content decreased and the malondialdehyde content increased. Further, Cd-induced hepatic structural damage and cell apoptosis were observed. However, Nar could alleviate liver damage caused by $\mathrm{Cd}$. Therefore, Cd caused oxidative damage and cell apoptosis in rat liver, while Nar had preventive and ameliorative effects on these injuries.
\end{abstract}

Key words: Apoptosis, Cadmium, Liver, Naringenin, Oxidative damage.

\section{INTRODUCTION}

Cadmium (Cd) is a common environmental toxicant that has harmful effects on plants, animals and humans (Nisha et al. 2009). In 1993, the International Agency for Research on Cancer classified $\mathrm{Cd}$ as human carcinogen I and the National Toxicology Program identified $\mathrm{Cd}$ as human carcinogen (Xiong et al. 2020). Cd is one of the most toxic heavy metals and a common industrial pollutant present in the environment (Adefegha et al. 2015). At present, the main sources of $\mathrm{Cd}$ are smoking tobacco and drinking contaminated water pollution (Soisungwan et al. 2013). Other sources include fertilizers, glass and batteries (Claudio et al. 2011). The biological half-life of $\mathrm{Cd}$ in the human body is up to 10-30 years (Kazuhiro et al. 2016) and the absorbed $\mathrm{Cd}$ mainly accumulates in the liver and kidney of the organism. The toxicity of $\mathrm{Cd}$ is mainly attributed to its damage to the redox system of the body (Stohs et al. 2000). Cd exposure leads to the change in mitochondrial membrane permeability, intensifies the occurrence of various apoptotic pathways and leads to apoptosis (Rahman et al. 2017). Naringenin (Nar) is a dihydroflavonol active ingredient found in Ruta plants. It is. Fruits, vegetables, tea and red wine are rich in Nar (Manchope et al. 2017). In addition, Nar has various biological activities, such as antioxidant, antiinflammatory and liver protection (Zhu et al. 2015). Therefore, some studies have found that $\mathrm{Nar}$ is an important ingredient for effective treatment of $\mathrm{Cd}$ poisoning (Manchope et al. 2017). However, no relevant report is available about the regulation of Nar on the caspase-dependent apoptosis pathway.

In this study, an acute Cd poisoning rat model was established via intraperitoneal injection of $\mathrm{CdCl}_{2}$ solution. The liver antioxidant index, liver pathological section and
College of Animal Science and Technology, Henan University of Science and Technology, Luoyang, China.

Corresponding Author: Jicang Wang, College of Animal Science and Technology, Henan University of Science and Technology, No. 263, Kaiyuan Avenue, 471023, Luoyang, PR China.

Email: wangjicang@126.com

How to cite this article: Wang, K., Ding, L., Kou, C., Huang, R., Zhao, P., Yang, Z. and Wang, J. (2021). Protective Effect of Naringenin on Cadmium-induced Toxicity in Rat Liver. Indian Journal of Animal Research. DOI: 10.18805/IJAR.BF-1425.

Submitted: 13-08-2021 Accepted: 06-10-2021 Online: 07-11-2021

mRNA expression of caspase- 3 and -9 were detected using real-time quantitative PCR (qRT-PCR) to evaluate the effect of $\mathrm{Cd}$ on the structure and function of rat liver and the preventive effect of $\mathrm{Nar}$ on liver toxicity caused by acute Cd-exposure. The results showed that subsequent use of plant polyphenol extract Nar could prevent and ameliorate Cd poisoning.

\section{MATERIALS AND METHODS Chemicals}

Anhydrous $\mathrm{CdCl}_{2}$ was purchased from Aladdin Industrial Corporation. Nar (purity: > 98\%) was obtained from Beijing Bailingwei Technology Co., Ltd (Beijing, China). Superoxide dismutase (SOD), catalase (CAT), glutathione (GSH) and malondialdehyde (MDA) kits were from Nanjing Jiancheng Bioengineering Institute, (Nanjing, China). TRlzol isolation kit and PCR primers were obtained from Sangon Biotech Co., Ltd (Shanghai, China). SYBR Premix Taq II kit was purchased from Takara (Beijing, China). All other routine chemicals and solvents were of pure analytical grade. 


\section{Animal treatment}

The experiment was conducted from August to December 2020 at the Environmental Animal Product Safety Laboratory of Henan University of Science and Technology, Luoyang, China. Adult male Sprague Dawley (SD) rats weighing 160-180 g were housed in polypropylene cages maintained at room temperature $\left(24^{\circ} \mathrm{C} \pm 2^{\circ} \mathrm{C}\right)$ on a 12 -h light/12-h dark cycle throughout the experiment. They were fed with a commercial standard diet, with free access to drinking water under standard laboratory conditions. The grouping and processing methods is shown in Table 1. All animal experimental processes were approved by the Institute of Zoology and Medical Ethics Committee of Henan University of Science and Technology and they were strictly designed under the consideration of animal welfares (approval number HAUST 19013).

Every weekend, the rat's body weight was recorded. The experiment lasted for 3 weeks. The rats were sacrificed by cervical decapitation $24 \mathrm{~h}$ after the last treatment. Liver tissues were removed from the sacrificed rats and washed in PBS. The tissues were fixed with $10 \%$ formalin for histopathological studies, frozen for qRT-PCR and crushed, homogenized $(10 \%, w / v)$ in PBS solution $(\mathrm{pH} 7.4)$ and centrifuged (3000 rpm for $10 \mathrm{~min}$ ) for various biochemical estimations.

\section{Histopathological studies}

Tissue samples of the liver was fixed in $10 \%$ formalin at $4^{\circ} \mathrm{C}$ for $24 \mathrm{~h}$. Then, different concentrations of ethanol were used as a dehydrating agent for step-by-step dehydration. The dehydrated liver tissues were embedded in paraffin. The paraffin blocks were sliced into 4-6 $\mu \mathrm{m}$ thick with a microtome. The obtained tissue sections were stained with hematoxylineosin and observed using an optical microscope.

Table 1: Grouping and processing methods $(n=6)$.

\begin{tabular}{ll}
\hline Groups & Processing methods \\
\hline control group & Given redistilled water + i. p. with $0.9 \% \mathrm{NaCl}$ \\
$0.5 \mathrm{mg} / \mathrm{kg} \mathrm{Cd}$ group & i. p. with $0.5 \mathrm{mg} / \mathrm{kg} \mathrm{b.w.} \mathrm{of} \mathrm{CdCl}_{2}$ \\
$1 \mathrm{mg} / \mathrm{kg} \mathrm{Cd}$ group & i. p. with $1 \mathrm{mg} / \mathrm{kg} \mathrm{b.w.} \mathrm{of} \mathrm{CdCl}_{2}$ \\
$2 \mathrm{mg} / \mathrm{kg} \mathrm{Cd}$ group & i. p. with $2 \mathrm{mg} / \mathrm{kg} \mathrm{b.w.} \mathrm{of} \mathrm{CdCl}_{2}$ \\
Nar group & Administered with Nar $(100 \mathrm{mg} / \mathrm{kg} \mathrm{b.w.)}$ \\
Nar +Cd group & Administered with Nar $(100 \mathrm{mg} / \mathrm{kg} \mathrm{b.w.)} \mathrm{+}$ \\
& i. p. with $2 \mathrm{mg} / \mathrm{kg} \mathrm{b.w.}$ \\
\hline
\end{tabular}

\section{Antioxidant analysis}

SOD, MDA, CAT and GSH activities were measured using the diagnostic kits in accordance with the manufacturer's protocol. These results were measured spectrophotometrically.

\section{mRNA expression}

Total RNA was extracted from the rat liver tissue by using a TRIzol reagent and the total RNA was reverse transcribed to synthesize cDNA. The primers were designed using Primer Premier 6 (Table 3). The instructions in the SYBR Premix Taq Gamma II Kit for qRT-PCR were followed. $\beta$ actin was used as endogenous control and the relative mRNA levels were analyzed using $2^{-\Delta \Lambda C T}$ method.

\section{Statistical analysis}

The data obtained under different experimental conditions were analyzed by one-way variance method in SPSS version 17. When $P<0.05$ or $P<0.01$, the difference was considered significant or highly significant, respectively.

\section{RESULTS AND DISCUSSION \\ Effect of Nar on Cd-induced changes in body weight}

Compared with the control group, the Cd groups decreased showed body weight. The body weight of the $1 \mathrm{mg} / \mathrm{kg} \mathrm{Cd}$ group decreased significantly $(P<0.05)$, while that of the 2 $\mathrm{mg} / \mathrm{kg}$ Cd group decreased highly significantly $(P<0.01)$, as shown in Table 2. However, after treatment with Nar (100 $\mathrm{mg} / \mathrm{kg}$ ) and Cd exposure for 2 and 3 weeks, the body weight significantly increased compared with that of the $2 \mathrm{mg} / \mathrm{kg}$ Cd group $(P<0.05)$.

\section{Histological assessment of liver tissues}

The results showed that the structure of liver tissues in the control group (Fig1A) was complete and normal, the shape was clear and the arrangement of hepatocytes was orderly. The Cd groups (Fig 1B-D) showed Cd-induced pathological changes in the liver tissue and irregular arrangement of hepatic cords, atrophic and necrotic hepatocytes, indistinct in space and extensively denatured and necrotic and some cell nuclei showed pyknosis. In the Nar group (Fig 1E), the morphology of liver tissue cells was normal and without any pathological phenomenon.

In the Nar + Cd group, a small amount of tissue showed slight hyperplasia or degeneration and the degree of damage was relieved compared with the Cd group (Fig 1F).

Table 2: Effects of Nar on Cd-induced changes in body weight $(g)(n=6)$.

\begin{tabular}{lcccc}
\hline Treated & Week 0 & Week 1 & Week 2 & Week 3 \\
\hline Control group & $164.5 \pm 5.9$ & $222.3 \pm 8.4$ & $277.7 \pm 9.2$ & $322.7 \pm 12.9$ \\
$0.5 \mathrm{mg} / \mathrm{kg}$ Cd group & $177.3 \pm 6.3$ & $227.7 \pm 5.9$ & $265.3 \pm 3.5$ & $308.8 \pm 3.8$ \\
$1 \mathrm{mg} / \mathrm{kg} \mathrm{Cd}$ group & $170.5 \pm 7.4$ & $207.7 \pm 9.5$ & $245.8 \pm 6.4^{*}$ & $291.2 \pm 10.7^{*}$ \\
$2 \mathrm{mg} / \mathrm{kg} \mathrm{Cd}$ group & $176.3 \pm 2.7$ & $180.0 \pm 2.6^{*}$ & $213.8 \pm 3.4^{* *}$ & $235.5 \pm 7.0^{* *}$ \\
Nar group & $172.7 \pm 3.9$ & $223.3 \pm 4.6$ & $274.3 \pm 4.8$ & $312.5 \pm 7.8$ \\
Nar + Cd group & $177.7 \pm 6.9$ & $183.3 \pm 5.3$ & $248.2 \pm 5.2^{* \# \#}$ & $269.0 \pm 6.5^{\star \#}$ \\
\hline
\end{tabular}

Date are presented as mean \pm SEM deviation. ${ }^{*} P<0.05$ or ${ }^{* *} P<0.01$ represents a significant difference or highly significant difference compared with the control group. ${ }^{\#} P<0.05$ or ${ }^{\#} P<0.01$ represents a significant difference or highly significant difference compared with the $2 \mathrm{mg} / \mathrm{kg}$ Cd group. 


\section{Effect of Nar on liver oxidative stress}

As shown in Fig 2, a significant $(P<0.05)$ decrease in the activities of enzymatic antioxidants (SOD and CAT) and the GSH content were observed in the Cd-treated rats. However, the MDA content was significantly higher $(P<0.05)$ and the $2 \mathrm{mg} / \mathrm{kg} \mathrm{Cd}$ group demonstrated a highly significant difference compared with the control group $(P<0.01)$. Compared with the $2 \mathrm{mg} / \mathrm{kg} \mathrm{Cd}$ group, the $\mathrm{Nar}+\mathrm{Cd}$ group showed that the activities of SOD and CAT increased highly significantly $(P<0.01)$ and the GSH content significantly increased $(P<0.05)$. However, the MDA content of the Nar + Cd group decreased highly significantly $(P<.01)$. No significant difference was found on these indicators between the Nar group and the control group $(P<0.05)$.

\section{Effect of Nar on caspase-9 and -3 mRNA expression}

The qRT-PCR results showed that $\mathrm{Cd}$ exposure induced an increase in the mRNA expression of caspase- 9 and -3 and the mRNA expression increased with the increase in $\mathrm{Cd}$

Table 3: Primer sequences of real-time PCR target genes.

\begin{tabular}{llr}
\hline Target gene & Primers sequences $\left(5^{\prime} \rightarrow 3^{\prime}\right)$ & Temperature \\
\hline Caspase-9 & F: TGCACTTCCTCTCAAGGCAGGACC & 66 \\
Caspase-3 & R: TCCAAGGTCTCCATGTACCAGGAGC & 60 \\
& F: GGGATGCCTTTGTGGACTATATG & \\
$\beta$-actin & R; TGAGCAGCGTCTTCAGAGACA & 63 \\
& F: GGAGATTACTGCCCTGGCTCCTA & \\
\hline
\end{tabular}

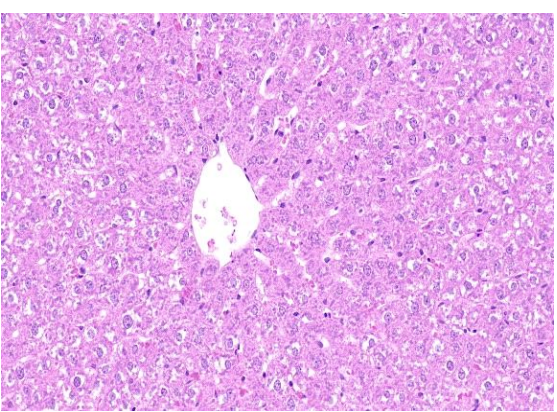

A

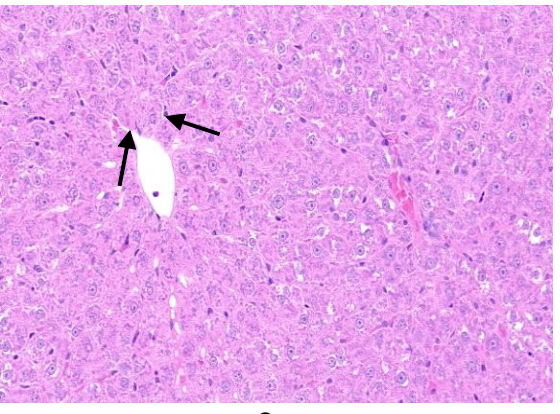

C

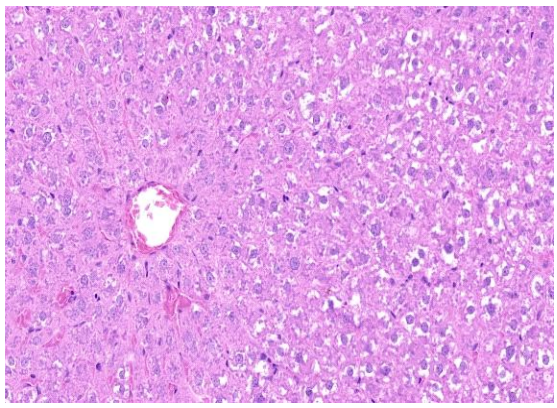

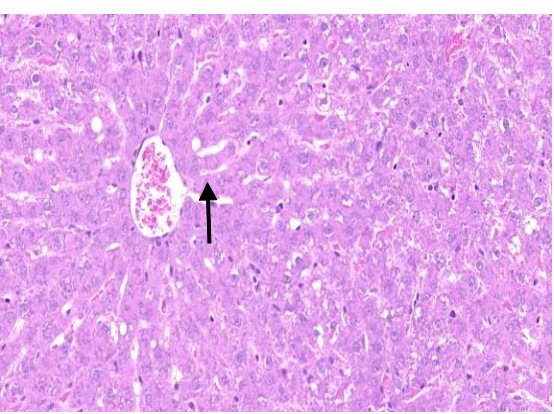

B
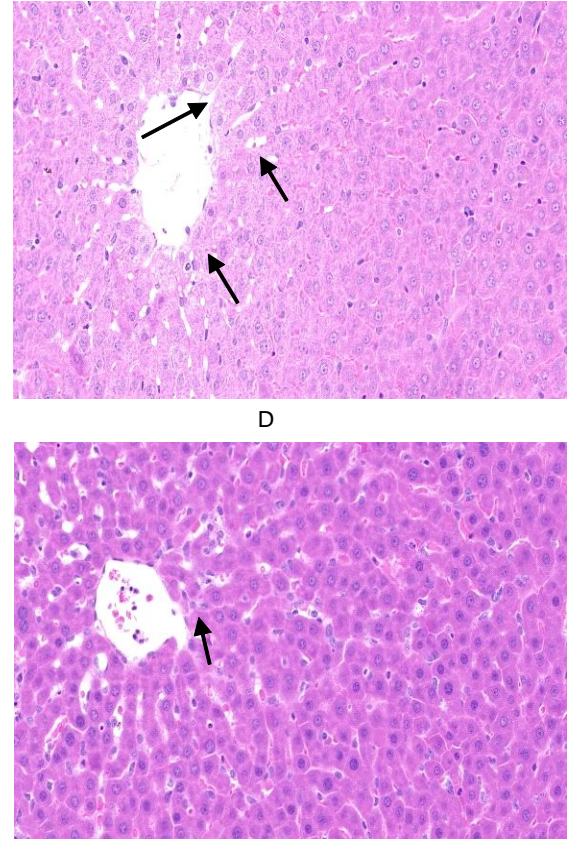

Fig 1: Pathological changes in liver tissue were observed by staining (40x).

A (control), B (Cd, $0.5 \mathrm{mg} / \mathrm{kg}$ b.w.), C (Cd, $1 \mathrm{mg} / \mathrm{kg} \mathrm{b.w.),} \mathrm{D} \mathrm{(Cd,} 2 \mathrm{mg} / \mathrm{kg} \mathrm{b.w.),} \mathrm{E} \mathrm{(Nar,} 100 \mathrm{mg} / \mathrm{kg}$ b.w.) and $\mathrm{F}(\mathrm{Nar}, 100 \mathrm{mg} / \mathrm{kg}+\mathrm{Cd}, 2 \mathrm{mg} / \mathrm{kg}$ b.w.). 
concentration (Fig 3). However, the level of caspase-9 and -3 mRNA expression was significantly lower $(P<0.05)$ in the $\mathrm{Nar}+\mathrm{Cd}$ group than in the $2 \mathrm{mg} / \mathrm{kg}$ Cd group.

$\mathrm{Cd}$ is one of the most widely used heavy metals in the contemporary world and its effect on the environment and humans are well known. Under Cd exposure, various organs of the body are affected to varying degrees, with liver being the most affected (Dkhil et al. 2014).

Body weight is regarded as an important indicator of animal health and weight gain depends on the supply and absorption of nutrients (Bhattacharya and Haldar. 2012). Cd exposure could lead to intestinal mucosal cell damage, thereby reducing the absorption and retention of nutrients. In addition, heavy-metal exposure may damage the glucocorticoid system and glucocorticoid system disorders could lead to weight changes (Akomolafe et al. 2016). In the present study, the fur of SD rats in the Cd-induced group was messy and dull. As shown in Table 2, the body weight of Cd-induced rats was significantly reduced compared with that of rats in the control group. These results are consistent with those of a previous study (Wang et al. 2019). The weight loss of rats may be due to the damage in the intestinal mucosa and the disorder of glucocorticoid system caused by Cd.

Histopathological changes could directly reflect liver injury. Cd exposure caused significant liver pathological changes and a comparable finding was made by Gong et al. (2019). This finding may be due to the accumulation of free radicals caused by $\mathrm{Cd}$ exposure, which eventually leads to organ damage (Skipper et al. 2016). Oxidative damage is the most representative of $\mathrm{Cd}$-induced liver damage; the $\mathrm{Cd}$ in the body induces tissues to produce reactive oxygen species (ROS), which reduces the organ's ability to respond to oxidative stress (Branca et al. 2018). In the past few years, Nar is one of the most popular antioxidants and it has shown that antioxidants could resist the toxicity of heavy metals (Zhang et al. 2012). In the present study, the levels of SOD, CAT, GSH and MDA were determined to illustrate the toxicity of $\mathrm{Cd}$ to the liver and the effect of Nar.

GSH resists oxidation by combining sulfhydryl groups with ROS and inhibiting the formation of ROS is the first line of defense for non-enzymatic antioxidants (Loro et al. 2012). SOD has the function of scavenging oxygen free radicals produced in the body. CAT is an important enzyme in the body's redox system and it could protect cells from the oxidative damage from $\mathrm{H}_{2} \mathrm{O}_{2}$ and $\mathrm{OH}^{-}$(Shahat et al. 2017). In the present study, the activities of CAT and SOD and the GSH content in the Cd-induced group were lower than those in the control group, indicating that $\mathrm{Cd}$ remarkably weakened the antioxidant capacity of the rat liver and the activities of CAT and SOD and the GSH content decreased in a dosedependent manner in liver treated with $\mathrm{Cd}$. Then, the rats
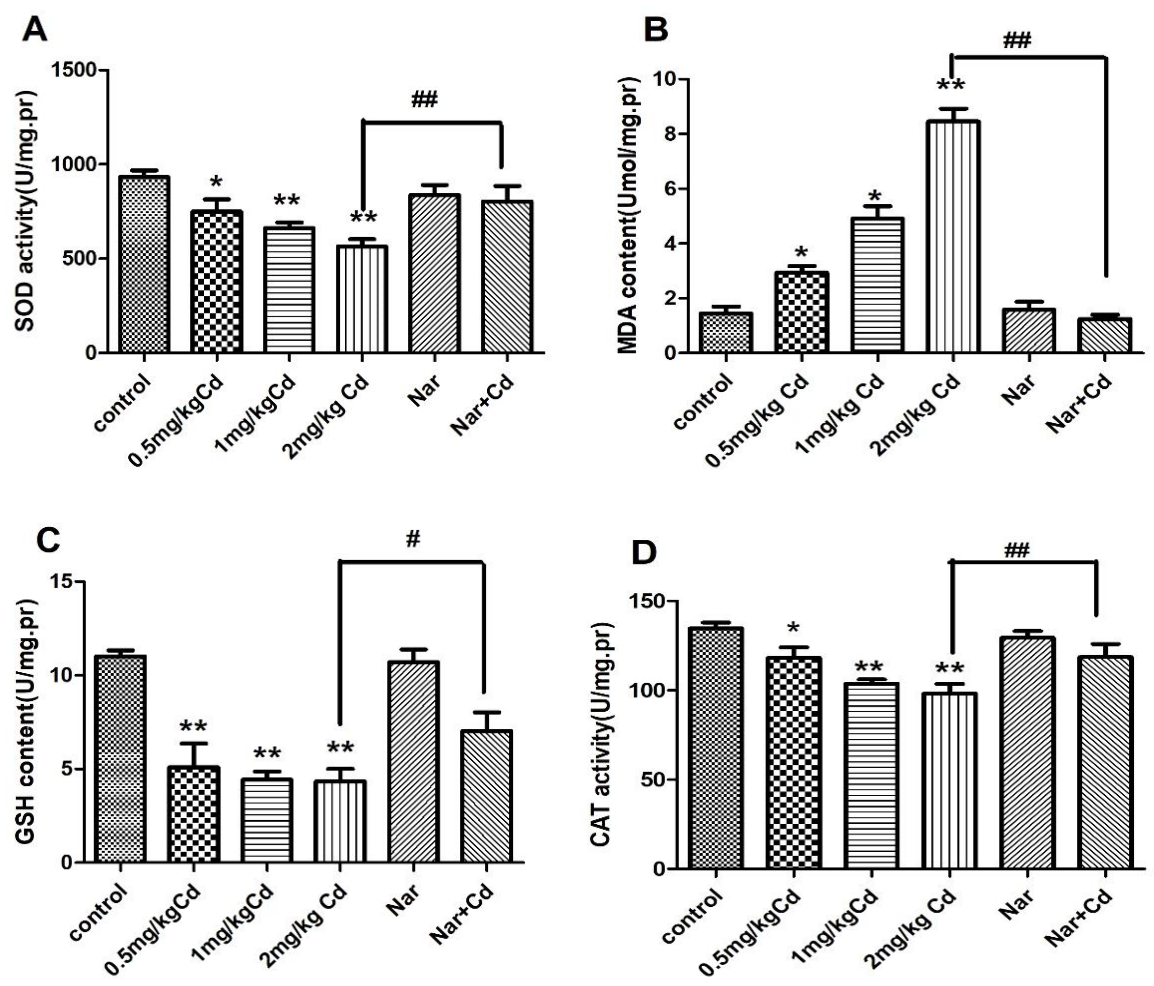

Fig 2: Effect of Nar on liver oxidative stress.

(A) SOD, (B) MDA, (C) GSH and (D) CAT. Date are presented as mean \pm SEM deviation. ${ }^{*} P<0.05$ or ${ }^{* *} P<0.01$ represents a significant difference or highly significant difference compared with the control group. ${ }^{\#} P<0.05$ or ${ }^{\#} P<0.01$ represents a significant difference or highly significant difference compared with the $2 \mathrm{mg} / \mathrm{kg} \mathrm{Cd}$ group. $\mathrm{n}=6$ in each group. 

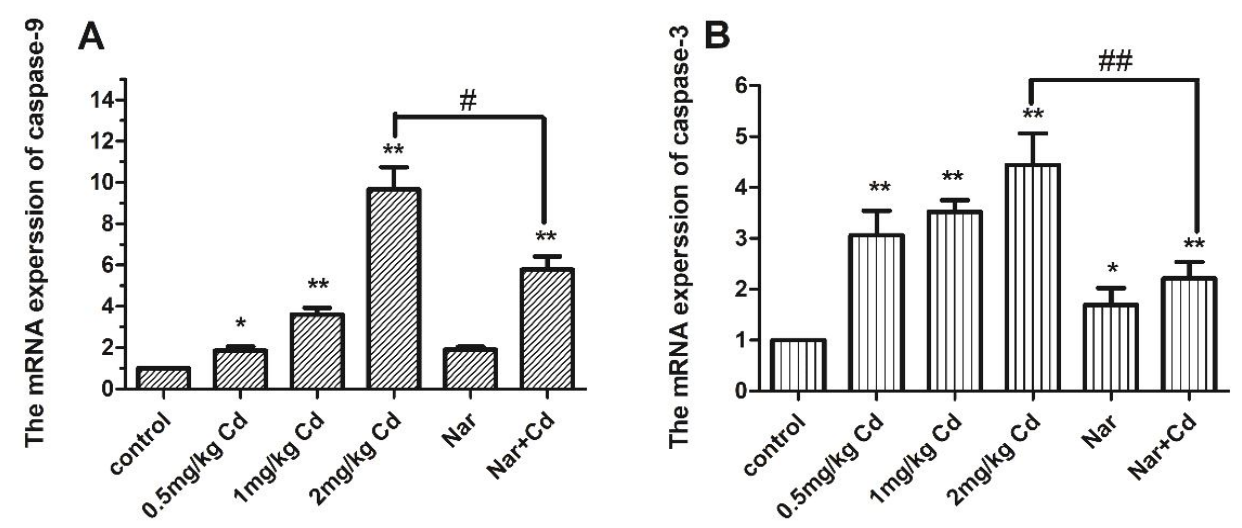

Fig 3: Expression of mRNA of caspase-9 (A) and caspase-3 (B) in the mitochondrial apoptosis pathway. Date are presented as mean \pm SEM deviation. ${ }^{*} P<0.05$ or ${ }^{* *} P<0.01$ represents a significant difference or highly significant difference compared with the control group. ${ }^{\#} P<0.05$ or ${ }^{\#} P<0.01$ represents a significant difference or highly significant difference compared with the $2 \mathrm{mg} / \mathrm{kg} \mathrm{Cd} \mathrm{group.} \mathrm{n}$ $=6$ in each group.

were administrated with $\mathrm{Nar}$ and $\mathrm{Cd}$. As shown in Fig 2, the activities of SOD and CAT between the Nar + Cd group and the $2 \mathrm{mg} / \mathrm{kg} \mathrm{Cd}$ group were highly significantly different $(P<0.01)$. The GSH content was also significantly different $(P<0.05)$. MDA is considered one of the biomarkers of oxidative stress (Zhang et al. 2014). Fig 2 shows that compared with the control group, the $\mathrm{Cd}$-exposed group had significantly increased MDA content and with the increase in Cd concentration, the difference became more significant. After Nar was administered, the MDA content in the Nar + $\mathrm{Cd}$ group decreased highly significantly compared with that in the $2 \mathrm{mg} / \mathrm{kg} \mathrm{Cd}$ group $(P<0.01)$. The above results indicated that $\mathrm{Cd}$ could cause oxidative damage to the liver and as an antioxidant, Nar could protect the liver and reduce Cd damage.

Several studies have reported that $\mathrm{Cd}$ induced mitochondrial caspase-dependent apoptotic gene expression, leading to cell apoptosis (Banik et al. 2019). However, whether Nar could inhibit Cd-induced liver cell apoptosis was unclear. Therefore, the mRNA expression levels of related apoptotic genes were analyzed in the present study. Cd-induced mitochondrial superoxides preferentially accumulate, leading to mitochondrial dysfunction and rupture of the outer membrane; cytochrome c (cyt-c) is released by the mitochondria; and caspase- 9 is activated and then cascades to activate caspase-3, causing caspase-dependent apoptosis (Kim et al. 2015). Caspase9 is an essential executor of the mitochondrial pathway to induce apoptosis and caspase- 3 is the key final executive molecule of various apoptotic methods and an important marker of apoptosis (Wu et al. 2020). In the present study, the mRNA expression levels of caspase- 9 and -3 in the $\mathrm{Cd}$ groups markedly increased compared with those in the control group, while those in the $\mathrm{Nar}+\mathrm{Cd}$ group were significantly lower than those in the $2 \mathrm{mg} / \mathrm{kg} \mathrm{Cd}$ group. Therefore, Cd could induce apoptosis in rat liver cells and increase the mRNA expression of caspase- 9 and -3 , while Nar suppresses Cd-induced apoptosis. In the mitochondrial apoptosis pathway, oxidative stress plays a key role in Cdinduced apoptosis (Wang et al. 2009). Therefore, as an antioxidant, Nar inhibits $\mathrm{Cd}$-induced apoptosis by reducing oxidative stress.

\section{ACKNOWLEDGEMENT}

This study was supported by grants from the National Nature Science Foundation of China (No.31972753).

\section{REFERENCES}

Adefegha, S.A., Omojokun, O.S., Oboh, G, Fasakin, O, Ogunsuyi, O. (2015). Modulatory effects of ferulic acid on cadmiuminduced brain damage. Journal of Evidence-Based Complementary and Alternative Medicine. 214: 56-61.

Akomolafe, R.O., Imafidon, C.E., Olukiran, O.S., Oladele, A.A. and Ajayi, A.O. (2016). Livolin Forte ameliorates cadmiuminduced kidney injury in wistar rats. Serbian Journal of Experimental and Clinical Research. 17: 107-116.

Banik, S., Akter, M., Corpus, B. S., Saito, T., Hosokawa, T., Kurasaki, M. (2019). Carvacrol inhibits cadmium toxicity through combating against caspase dependent/independent apoptosis in PC12/ cells. Food and Chemical Toxicology. 134: 110835.

Bhattacharya, S. and Haldar, P. (2012). Trichosanthes dioica fruit ameliorates experimentally induced arsenic toxicity in male albino rats through the alleviation of oxidative stress. Biological Trace Element Research. 148: 232-41.

Branca, J., Morucci, G., Maresca, M., Tenci, B., Cascella, R., Paternostro, F., Ghelardini, C., Gulisano, M., Mannelli, L., Pacini, A. (2018). Selenium and zinc: Two key players against cadmium-induced neuronal toxicity. Toxicology In vitro. 48:159-69.

Claudio, L., Rosalia, S., Alessandra, L. (2011) Cadmium as a transcriptional modulator in human cells. Critical Reviews in Toxicology. 411: 75-82. 
Dkhil, M.A., Al-Quraishy, S., Diab, M.M.S., Othman, M.S., Aref, A.M., Moneim, A.E.A. (2014). The potential protective role of Physalis peruviana L. fruit in cadmium-induced hepatotoxicity and nephrotoxicity. Food and Chemical Toxicology. 74: 98-106.

Gong, Z.G., Wang, X.Y., Wang, J.H., Fan, R.F., Wang, L. (2019). Trehalose prevents cadmium-induced hepatotoxicity by blocking Nrf2 pathway, restoring autophagy and inhibiting apoptosis. Journal of Inorganic Biochemistry. 192: 6271.

Kazuhiro, N., Yasushi, S., Masao, I., Keiko, A., Rie, O., Muneko, N., Hideaki, N., Teruhiko, K. (2016). Attenuation of urinary cadmium in inhabitants of the environmentally exposed jinzu river basin determined by applying a mixed linear model. Bulletin of Environmental Contamination and Toxicology. 96: 699-703.

Kim, S., Park, K., Choe, J. (2015) Oxidative stress by monosodium urate crystals promotes renal cell apoptosis through mitochondrial caspase-dependent pathway in human embryonic kidney 293 cells: mechanism for urate-induced nephropathy. Apoptosis. 201: 38-49.

Loro, V.L., Jorge, M.B., Silva, K.R., Wood, C.M. (2012). Oxidative stress parameters and antioxidant response to sublethal waterborne zinc in a euryhaline teleost fundulus heteroclitus: Protective effects of salinity. Aquatic Toxicology. 110: 18793.

Manchope, M.F, Casagrande, R., Verri, W.A. (2017) Naringenin: An analgesic and anti-inflammatory citrus flavanone. Oncotarget. 83: 3766-7.

Nisha, A.R., Nair, A.M.C., Gopakumar N. and Joy, A.D. (2009). Assessment of cadmium concentration and its relation with serum biochemical parameters in cattle in cadmium industrial effluent contaminated area. Indian Journal of Animal Research. 43:206-208.

Rahman, M., Ukiana, J., Uson-Lopez, R., Sikder, M., Saito, T. and Kurasaki, M. (2017). Cytotoxic effects of cadmium and zinc co-exposure in PC12 cells and the underlying mechanism. Chemico-Biological Interactions. 269: 4149.

Shahat, A.N.E., Azeem, A.M.A., Mekawey, H.M.S., El-megid, M.H.M.A. (2017). Studying the effect of $g$-irradiated celery leaves on antioxidant status and cardiac enzymes in hypercholesterolemic rats. Indian Journal of Animal Research, DOI:10.18805/ijar.v0iOF.9146.
Skipper, A., Sims, J., Yedjou, C., Tchounwou, P. (2016). Cadmium chloride induces DNA damage and apoptosis of human liver carcinoma cells via oxidative stress. International Journal of Environmental Research and Public Health. 13: 88.

Soisungwan, S., Witaya, S., Werawan, R., Muneko, N., Patricia, R. (2013) Modeling cadmium exposures in low- and highexposure areas in Thailand. Environmental Health Perspectives. 121: 531-6.

Stohs, S.J., Bagchi, D., Hassoun, E., Bagchi, M. (2000). Oxidative mechanisms in the toxicity of chromium and cadmium ions. Journal of Environmental Pathology, Toxicology and Oncology. 19: 201-13

Wang, L., Cao, J., Chen, D., Liu, X., Lu, H., Liu, Z. (2009). Role of oxidative stress, apoptosis and intracellular homeostasis in primary cultures of rat proximal tubular cells exposed to cadmium. Biological Trace Element Research. 1271: 53-68.

Wang, J., Zhu, H., Zhang, C., Wang, H., Yang, Z. (2019) Baicalein ameliorates cadmium-induced hepatic and renal oxidative damage in rats. Indian Journal of Animal Research. 53: 523-527.

Wu, P., Song, Q., Yu, Y., Yu, H., Luo, H., Tan, S. (2020). Effect of metformin on mitochondrial pathway of apoptosis and oxidative stress in cell model of nonalcoholic fatty liver disease. Chinese Journal of Hepatology. 281: 64-8. Chinese

Xiong, X, Zhang, Y., Xing, H., Xu, X. (2020) Ameliorative effect of selenomethionine on cadmium-induced hepatocyte apoptosis via regulating pi3k/akt pathway in chickens. Biological Trace Element Research. 195: 559-68.

Zhang, H., Cai, C., Shi, C., Cao, H., Han, Z., Jia, X. (2012). Cadmium-induced oxidative stress and apoptosis in the testes of frog Rana limnocharis. Aquatic Toxicology. 15: 67-74.

Zhang, H., Pan, L., Tao, Y. (2014). Antioxidant responses in clam venerupis philippinarum exposed to environmental pollutant hexabromocyclododecane. Environmental Science And Pollution Research International. 113: 8206-15.

Zhu, L., Wang, J., Wei, T., Gao, J., He, H., Chang, X., Yan, T. (2015). Effects of Naringenin on inflammation in complete freund's adjuvant-induced arthritis by regulating Bax/Bcl-2 balance. Inflammation. 38: 245-51. 